\title{
Research on the Teaching Reform of Programming Courses Based on Robotics Education in High School
}

\author{
Xiulin Ma1, Chenyu Fan'1, Sheng Li2 ${ }^{2}$, Yujuan Jia1 \\ ${ }^{1}$ Faculty of Education, Beijing Normal University, Beijing, China \\ ${ }_{2}^{2}$ Joint Laboratory by Ministry of Education, China Mobile Company, Beijing, China \\ Email: maxl@bnu.edu.cn, ssfanlmz@163.com, *lisheng@chinamobile.com, Jyujuan8807@163.com
}

How to cite this paper: Ma, X. L., Fan, C. Y., Li, S., \& Jia, Y. J. (2020). Research on the Teaching Reform of Programming Courses Based on Robotics Education in High School. Creative Education, 11, 2305-2326. https://doi.org/10.4236/ce.2020.1111169

Received: September 28, 2020

Accepted: November 15, 2020

Published: November 18, 2020

Copyright $\odot 2020$ by author(s) and Scientific Research Publishing Inc. This work is licensed under the Creative Commons Attribution International License (CC BY 4.0).

http://creativecommons.org/licenses/by/4.0/

\begin{abstract}
Programming is of great importance to the cultivation of computational thinking and logical thinking ability. However, the programming course in the middle school stage has been unpopular for years among most students. There are two reasons that contribute to this phenomenon: First, teachers paid more attention to grammar teaching than computational and logical thinking; second, students perceived that the content of programming course was not important, and unrelated to actual situation, and not enthusiastic for programming course. Out of fear about debugging, students tend to have lower intention for getting good grades or attain programming skills. Under these circumstances, this research introduced robot design and application into programming courses for students in high school, using robot teaching as a carrier, and integrating the cultivation of logical thinking into teaching. Carrying out teaching practice and related research with robot education as the carrier, this study succeeds in stimulating students' sense of self-efficacy in the field of programming, cultivating students' logical thinking ability, scientific research ability, and developing their scientific inquiry spirit.
\end{abstract}

\section{Keywords}

Robotics Education, Program Design, Logical Thinking

\section{Introduction}

1.1. Computational Thinking and Logical Thinking Are of Great Significance to Talent Training in the Era of Big Data

As a compound ability in the 21 st century, computational thinking (CT) has 
gradually become the focus of current information technology education (Li, Zhang, Huang, Zhang, Zhang, \& Wang, 2019). Computational thinking is not just the exclusive skills of computer scientists, but the basic skills that everyone should have in the digital age. The cultivation of computational thinking ability is of great significance to the current teaching of basic computer courses in universities, and the thinking and manipulation methods in computer science are of great value to the cultivation of modern talents. Logical thinking is the core content of computational thinking. Using computational thinking and logical thinking to solve problems is an important means of innovation. Many practical problems in the era of big data show obvious characteristics of computer science, and analyzing and solving these problems require good computational and logical thinking skills.

\subsection{The Difficulties Faced by the Teaching of High School Programming Courses}

Learning to transform actual problems into problems that computers can solve and learning how computers solve problems are an important part of computational thinking. In this process, it is very important to master the working principle and internal logic of the computer, and program design is the main means to achieve this goal. However, in the specific teaching practice, the programming curriculum of high school students faces many difficulties.

1) Common phenomena in high school students' programming lessons

There are many problems in the teaching of programming course such as $\mathrm{C}$ Language. a) Many cumbersome grammars are involved in the process of program design which makes students feel extremely frustrated; b) most students often recite the program mechanically, and cannot master the internal logic and basic principles of the program in depth; c) most students can only correct simple grammatical errors, they can't debug the program and solve the logic problems inside the program. d) Some software is difficult to meet the needs of senior middle school students in logical thinking development in terms of logical rigor, content complexity and solving practical problems.

2) The deep-seated reasons for the unsatisfactory effects of programming lessons for high school students

The investigation found that lack of interest and motivation in programming is the fundamental reasons that affect the learning quality of programming courses, and is also the deep-seated reason why the programming effect of primary and middle school students is not satisfactory. At first, the program code is obscure and difficult to understand, learning is difficult to apply, and students' sense of self-efficacy is reduced, and then gradually losing interest in learning. Secondly, most of the teaching cases have no practical application, so the students' learning motivation is insufficient. Furthermore, it is difficult for students to be proficient in traditional teaching methods and application structure, which causes teachers to gradually lose their enthusiasm for teaching and students 
gradually lose their motivation to learn.

\subsection{Robot Teaching Has Become an Important Part of STEM Education}

Robotics education has become an important part of STEM education. Robotics education is a course derived from the "simple robot building" module. The purpose of robotics education is to expose students to robotics and to break the mystery of technology. Students master the basic process and thinking methods of robotics building by personally designing and building robots. Specific tasks-based teaching improves students' learning methods, improve their interest in learning, stimulates desire to continue to explore robotics, and cultivates innovative thinking and practical ability, laying a good foundation for students' continuing education and lifelong development.

From the perspective of the teaching practice of robotics education, most students are very interested in robot design and control. They want to design and control robots themselves, and they all have a strong learning motivation.

\subsection{Research Problems}

The design, control and operation of the robot are inseparable from the control of "program code". The logical thinking ability of the students participating in robot learning has developed rapidly, and students' programming ability has also been rapidly developed. Therefore, this research is based on the hypothesis that "robot teaching can promote the development of students' logical thinking ability" to explore effective strategies to solve the current difficulties faced by high school students' programming courses. This study focuses on the following issues.

1) To explore the effective mode of integrating programming concept into robot teaching and realize the win-win situation of developing programming ability and robot teaching quality.

2) To explore the evaluation model of robot learning quality and logical thinking ability development, and form rigorous and scientific research conclusions, in order to provide support for subsequent iterative research.

3) To verify the actual utility of robot supporting information technology teaching for cultivating students' logical thinking ability, improving students' sense of self-efficacy and scientific research ability.

\section{Literature Review}

\subsection{Research Status of Program Design Courses}

In recent years, programming courses such as Java programming, VB programming, $C$ programming, Python programming, etc. have not only been widely offered in colleges and universities, but have also gradually entered primary and secondary schools. High-level language programming is a basic course for college information technology majors, among which $\mathrm{C}$ language programming is a 
very logical and practical course. GORRIERI Andrea pointed out that C language program teaching based on computational thinking should teach the computational thinking described in it when imparting relevant knowledge points. The implementation of strengthening and cultivating computational thinking can improve students' $\mathrm{C}$ language learning ability and computational thinking ability (Gorrieri \& Ferrari, 2015). Some scholars have also proposed that $\mathrm{C}$ as an introductory language interferes with the object-oriented way of thinking that students will use in the future; most students have little understanding of various programming languages, and none of them are proficient. The actual programming ability needs to be improved. The training goal is contrary to the goal; the goal of connecting with foreign computer majors is not achieved (Lan \& Zheng, 2012). VB courses have always been the main program course content for primary and secondary school learning. However, some researches have shown that VB courses "belong to an object-oriented concept, and traditional teaching methods will not meet the needs of modern teaching (Zhang \& Zhao, 2012)." The teaching of VB courses basically follows the traditional teaching method of "teaching-oriented". The curriculum is seriously out of touch with the practical computer-based curriculum, resulting in students not being able to apply and master the knowledge they have learned in time. The knowledge learned during the practical operation of the computer is not well consolidated, and even at a loss when facing the computer, further a vicious circle, and completely lose the interest and enthusiasm of learning (Zhang, Duan, Zhou, \& Li, 2019). In the process of information technology teaching in elementary and middle schools, the teaching content of algorithm and program design has always been a difficult point. The biggest reason is that the difficulty of introductory learning of teaching languages such as VB and C used in traditional teaching is too difficult, and the teaching content of program courses is boring. In addition to the monotonous output of program instructions, there is a lack of practical applications in life. Most students find it difficult to raise interest in learning, and the natural teaching effect is not satisfactory.

In the context of the establishment of artificial intelligence courses at the primary and secondary levels of the Premier of the State Council, various primary and secondary schools immediately began a wave of learning programming courses, and Python courses have gradually become an alternative language for beginners (Alshaigv, 2013). But Python also has many problems in teaching. Studies have shown that students are not very clear about the goal of learning the course, do not know what they can do after learning the course, and are at a loss as to what they can do after learning the Python language, which indirectly leads to insufficient learning motivation and directly affects the learning effect (Liu, Xu, \& Zhou, 2017). The emergence of the Scratch programming language makes programming easier, and provides a good language tool for programming teaching in primary and secondary schools. Existing research mainly explores how Scratch conducts cognitive construction for learners in 
the process of learning programming knowledge, and studies the effectiveness of Scratch for learners' logical thinking ability, creative thinking ability, and deep psychological generation mechanism. In recent years, also gradually researched the maker concept generated by the combination of Scratch and hardware devices (He, 2018). However, the structure of Scratch programming is relatively simple, which is more suitable for students in elementary school or lower grades of middle school, and not suitable for programming courses of upper middle school.

\subsection{Research on Robotics Education}

Igor M. Verner is committed to researching the value of project-based robotics education. Igor M. Verner regards robot competition as a form of project learning, discussing the background of robot teaching field and the characteristics of robot teaching, namely learning motivation, problem solving, interdisciplinary learning methods, teamwork, etc. (Verner, 1998). Illah R. Nourbakhsh, Kevin Crowley introduced an extensive robotics course, discussed methods for evaluating the effectiveness of robotics education, and finally guided students to design an effective, low-cost robot (Nourbakhsh, Crowley, Bhave, Hamner, Hsiu, Perez-Bergquist, et al., 2005). Dilek Karahoca, Adem Karahoca, Huseyin Uzunboylub, etc. conducted research on robotics education to support elementary science and technology courses and put forward that "robotics education supports students' lives, and students have active performance in science courses (Karahoca, Karahoca, \& Uzunboylub, 2011)". The research direction of Manvendra Singh Raghav, Shailesh Jain, Subir Kumar Saha, etc. is "robotics education based on robot competition", they believe that robot competition can promote the development of robotics education (Singh, Jain, \& Saha, 2008). Aleksandr Sergeyev and Nasser Alaraje discussed how to promote robotics education from two aspects: robotics course development and advanced robotics laboratory construction (Sergeyev \& Alaraje, 2010). Brigitte Denis*, Sylviane Hubert discussed cooperative learning in a robotics education environment. They believe that robotics education has a multi-level goal, not only to enable learners to acquire specific skills such as knowledge and robot integrated circuits, but also to develop their dynamic composite capabilities, such as design and development project cooperation capabilities and problem-solving ability (Denis \& $\mathrm{Hu}$ bert, 2001). The domestic research materials on "robotics education" are very rich, and the research fields are also very wide. They mainly conduct in-depth research from robot teaching, robot teaching materials construction, robot competition, and robot laboratory construction. Robotics education has been widely carried out in our country's primary and secondary schools. In September 2005, Harbin introduced robots into classroom teaching throughout the city, making robot science education a compulsory course for elementary, middle and high school students (Zhang \& Wang, 2006). Liu Jie discussed the significance of developing school-based robotics textbooks, the teaching con- 
tent of robotics school-based textbooks, and the teaching mode of robotics education (Liu, 2009). Peng Minxia elaborated on the design and development of primary school robot teaching materials from the aspects of "the importance of primary school robotics education, the status quo of primary school robotics education, the main influencing factors of robotics education and the use of robot teaching materials" (Peng, 2009). In the research on the educational value of robotics competitions, $\mathrm{He} \mathrm{Zhi}, \mathrm{Hu}$ Younong \& Allen believe that "the robotics competition has cultivated students' abilities, improved educational methods, stimulated students' learning motivation, cultivated students' teamwork spirit, and shaped students the character of tolerance" (He, Hu, \& Allen, 2006). Wang Yingqin discussed the construction of the robot laboratory from the aspects of "how to build a robot laboratory in primary and secondary schools, and the equipment plan of the robot laboratory in primary and secondary schools" (Wang, 2004).

\section{Methodology}

\subsection{Research Objectives}

Introducing robotics education into programming teaching can cultivate students' innovation ability of planning and design, hands-on practice, collaboration and cooperation, logical thinking, analyzing and solving problems. The research focused on cultivating students' practical, logical thinking and scientific research ability by constructing and implementing the teaching scheme of programming course supported by robotics education in high school.

1) Cultivate students' practical ability

High score but low ability is a common problem among high school students. This research hopes that under the premise of robotics education, organize students to play with live robots by themselves, and further train students' basic skills, cultivate their practical ability and get them out of the cycle of "high score but low ability".

2) Train students' logical thinking ability

Programming has natural advantages for cultivating students' logical thinking ability. Through robot programming training, students' logical thinking ability can be cultivated purposefully, planned and step by step.

3) Cultivate students' scientific research ability

Robotics education supports the research of information technology teaching in high school requires students to carry out robot experiments and develop robot program with a scientific and rigorous attitude, which enhances students' scientific literacy and interest in science, and lays the foundation continued search for scientific truth.

4) Improve the teaching effect of IT

With the interest, practicality, playfulness, exploratory and experiment of robotics education, it can promote students' active learning and improve the 
classroom teaching effect of IT (information technology).

\subsection{Participants}

This research selected high school sophomore students whose Enrollment date was 2017 and 2018 respectively as the research objects participants. The students of grade 2017 (control class) were mainly taught $C$ language programming by traditional "lecture-practice" method, while the students of grade 2018 (experimental class) were taught by robot design supported by $\mathrm{C}$ language programming.

To ensure the effectiveness of quasi-experimental research, two rounds of teaching activities were strictly designed and restricted. There were 21 classes in each grade, of which there were 715 participants in control class and 707 in experimental class. There were 360 males and 355 females in the control class, and 355 males and 352 females in the experimental class. Therefore, there was no significant difference between the experimental class and the control class in terms of class size and gender composition.

\subsection{Instruments}

Before carrying out the teaching experiment, the experimental class and the control group used the "academic questionnaire" to test. The results show that there is no significant difference between the two class of students in their original knowledge base, attitude towards programming, and understanding of robots.

There was no difference in teaching objectives and learning contents between the two classes. The teachers responsible for the teaching content were all full-time teachers of the Information Technology Teaching and Research Group of the school, and each teacher must undertake the teaching task of both the experimental class and the control class.

\subsubsection{Teaching Platform}

The robot used in this study came from the JoinMax Company which provided a full-service platform called RoboExp (Robot Express) to support writing and debugging soccer robot programs. The programming environment of RoboExp had graphical programming tools and program code editors. This study required students to use the code programming environment to write robot programs, to achieve a close integration with the idea of "algorithm and programming".

\subsubsection{Academic Proficiency Test}

Students' academic performance is the quality core of basic education, which is the education quality setting logic controlled by basic education teaching quality (Ran, 2018). Academic achievement is the final measure of teaching quality. It is necessary to check whether the students have completed the three-dimensional learning goals, especially the knowledge and goal requirements, which are mainly reflected by the students' academic performance test results. 
The Guangdong Provincial High School Information Technology Curriculum Academic Proficiency Test was used to test the academic level of subjects. As an authoritative test organized by the provincial education department, the reliability and validity were self-evident.

\subsubsection{Academic Questionnaire}

In order to evaluate students' comprehensive literacy and self-efficacy on programming, the academic survey questionnaire was developed based on Learning and Study Strategies Inventory (LASSI), General Self-Efficacy Scale (GSES), CUCEI scale, and in combination with the teaching practice of programming. The dimensions of this questionnaire include basic information, attitude, expectation, self-assessment and self-efficacy. Among them, the self-efficacy dimension included 10 issues of GSES, with the qualifier "program design" was added in description. In other dimensions, the LASSI and CUCEI were reduced appropriately. Besides, a few questions were added to make it more in line with this study. Among them, the dimension of self-efficacy included 10 topics of GSES, only adding "programming" qualifier on the topic, while other dimensions made appropriate reduction on LASSI and CUCEI, and added several questions, making them more consistent with this study.

The academic situation questionnaire was mainly formed by referring to the authoritative scale. Three authoritative experts in the field of educational technology were invited to make a review, which ensured the structural validity and authority of the questionnaire. Pilot test was conducted to evaluate the reliability, with the value of Kaiser-Meyer-Olkin (KMO) is 0.792 , and the result of factor analysis indicated that the structural validity of this questionnaire was qualified.

\subsubsection{Evaluation}

Collecting learners' cognitive style and preliminaries through pre-test to complete learner analysis and formulate instructional design plans and group learning plans. At the end of the experimental study, the post-test was conducted to detect the learner's learning situation. Combining data of pro-test and pre-test, students' achievements in robotics education, learning style and changes in autonomous learning ability and other factors were used to evaluate the final effect of this study. Therefore, this study mainly evaluates the effectiveness of teaching practice from the following three dimensions: academic performance, students' understanding and attitude to program design, and students' level of self-efficacy in program design.

\subsection{Procedure}

Using task-driven teaching method, the teaching activities were carried on specific tasks, which was based on robotics education. In this study, three rounds of teaching activities were launched. Each round included three stages, which were instructional design, implementation, and reflection. In order to cultivate logical thinking, the first stage mainly focused on learners and shaped their awareness 
of problem-solving by computational thinking. In the second stage, learning scenarios and processes were designed based on academic survey. Finally, reflection and analysis were carried out based on the data of the experimental class and the control class (Figure 1).

1) Practice teaching.

Based on robot, the teaching practice was carried on experimental and control class. In the experimental class, inquiry learning was organized by using lecture, discussion, and task-driven method. Students were encouraged to compete with others. While the control class mainly adopted traditional teaching method. Students were required to accomplish specific tasks assigned by teachers within the prescribed time.

2) Teaching effect of the course.

The effect of teaching was checked through periodic tests, interview, and teaching reflection, towards the whole process of teaching.

3) Feedback

In the process of teaching practice, the questionnaire data were used to conduct post-test on the students from the dimensions of knowledge mastery, student learning analysis, self-efficacy and so on, in order to form some feedback opinions. Feedback is multifaceted and specific, and has a certain practical utility.

4) Improvement

Based on the feedback data, improve and perfect the teaching activities of the experimental class in order to obtain better teaching effects. Curriculum teaching itself should be a dynamic and iterative process and should be adjusted in time according to the actual teaching situation.

\section{Teaching Experiment}

After the introduction of robots in the "Algorithm and Programming" course, the teaching content should also be adjusted accordingly. First of all, we should

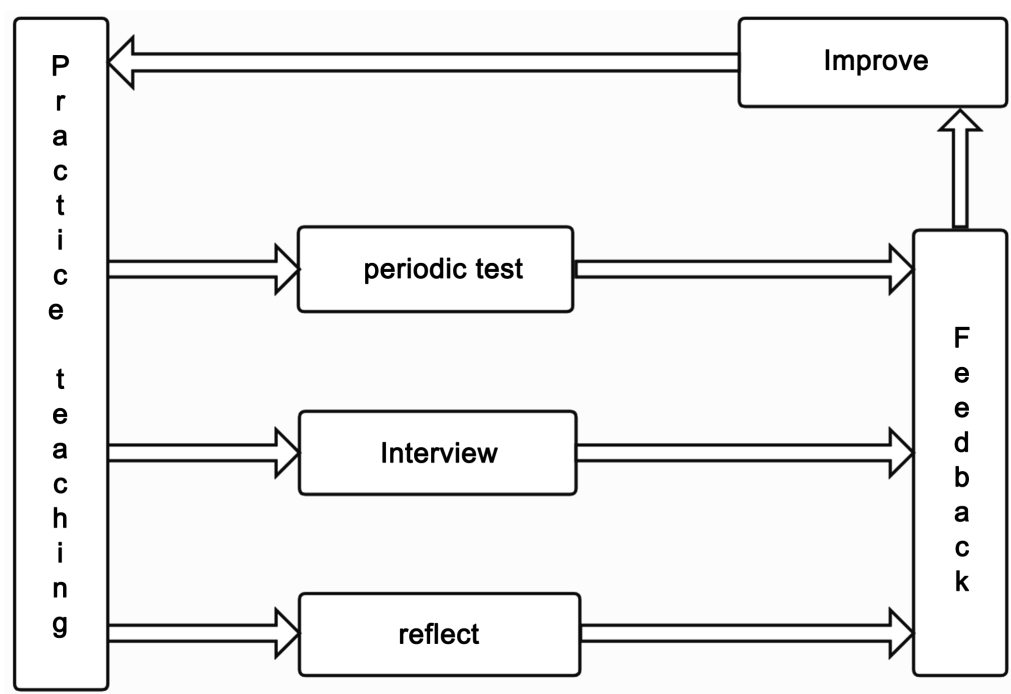

Figure 1. Course teaching implementation process. 
understand and be familiar with the robot, then start the teaching of the "algorithm and programming" course on the basic of familiarity with the robotic environment, let the robot penetrate the teaching of the "algorithm and programming" course, and then learn, practice and understand the basic idea of programming.

This research selected three typical cases as the problem environment for the teaching of algorithm and programming courses, namely "Soccer Robot", "Sweeper Robot" and "Restaurant Robot". In view of the length of the article, this article mainly elaborated on the design and organization of the "Soccer Robot" teaching activities.

\subsection{Design of Soccer Robot Teaching Activities for Logical Thinking Training}

\subsubsection{The Teaching Experiment Framework of "Soccer Robot"}

Design a teaching experiment framework as shown in Table 1 for "Soccer Robot", and strive to create a real experimental scenario for experimental activities,

Table 1. Teaching experiment design framework.

\begin{tabular}{|c|c|c|c|}
\hline Experiment & Design idea & $\begin{array}{l}\text { Experimental } \\
\text { strategy }\end{array}$ & $\begin{array}{l}\text { Experimental } \\
\text { intention }\end{array}$ \\
\hline $\begin{array}{c}\text { Soccer } \\
\text { Robot } \\
\text { Construction }\end{array}$ & $\begin{array}{l}\text { Teachers provide robot } \\
\text { motion videos; students } \\
\text { observe and analyze the defects } \\
\text { of robots; work in small groups } \\
\text { to prepare for experiments; } \\
\text { cooperate in teams to assemble } \\
\text { robots and think about its } \\
\text { design principles; improve } \\
\text { and demonstrate robots }\end{array}$ & $\begin{array}{l}\text { Play videos to show the } \\
\text { movement status of the } \\
\text { defective robot; students } \\
\text { control the experiment } \\
\text { process independently; } \\
\text { teachers supervise, } \\
\text { guide and remind }\end{array}$ & $\begin{array}{c}\text { Cultivate students' } \\
\text { practical ability }\end{array}$ \\
\hline $\begin{array}{c}\text { ForLoop } \\
\text { Teaching } \\
\text { Experiment }\end{array}$ & $\begin{array}{l}\text { Students combine the essentials } \\
\text { of knowledge and robot } \\
\text { behavior to visually show } \\
\text { the execution process of the } \\
\text { For loop; the teacher leads } \\
\text { the students to track the } \\
\text { execution process of the } \\
\text { For loop }\end{array}$ & $\begin{array}{l}\text { The teacher adopts the } \\
\text { task-driven method to } \\
\text { guide students to carry } \\
\text { out inquiry learning } \\
\text { activities; the task } \\
\text { design has a clear } \\
\text { hierarchy, from the } \\
\text { shallower to the deeper, } \\
\text { which effectively drives } \\
\text { the students to carry out } \\
\text { the learning activities }\end{array}$ & $\begin{array}{l}\text { Cultivate } \\
\text { students' logical } \\
\text { thinking ability }\end{array}$ \\
\hline $\begin{array}{c}\text { Offensive } \\
\text { Robot }\end{array}$ & $\begin{array}{l}\text { Guide students to decompose } \\
\text { this experiment into subtasks } \\
\text { such as adjustment, positioning, } \\
\text { finding the ball, chasing the ball, } \\
\text { shooting and returning to the } \\
\text { goal; teamwork, design } \\
\text { algorithms, write programs, } \\
\text { and debug programs for each } \\
\text { task; effectively integrate the } \\
\text { programs of each subtask to } \\
\text { achieve Offensive robot }\end{array}$ & $\begin{array}{l}\text { The teacher adopts the } \\
\text { task-driven method to } \\
\text { guide students to } \\
\text { gradually enter the } \\
\text { experimental state, } \\
\text { independently analyze } \\
\text { subtasks, design } \\
\text { algorithms, and write } \\
\text { programs; students help } \\
\text { each other to learn }\end{array}$ & $\begin{array}{l}\text { Cultivate } \\
\text { students' } \\
\text { scientific } \\
\text { research ability } \\
\text { and logical } \\
\text { thinking ability }\end{array}$ \\
\hline
\end{tabular}


allowing students to practice and explore independently in the experimental scenario, in order to exercise their hands-on practice ability, logical thinking ability and scientific research ability.

\subsection{2. "Soccer Robot" Comprehensive Practice Activity Design}

Comprehensive practice is to comprehensively use programming ideas to solve practical problems of soccer robots.

1) Comprehensive Practice 1: Offense

Task description: In the robot soccer field, freely complete the actions of chasing the ball, attacking, shooting and returning to the goal.

Task analysis: As shown in Figure 2, the robot needs to rely on its own sensory devices to measure various environmental conditions, and then judge according to various conditions to complete the actions of chasing the ball, attacking, shooting, and returning. Firstly, the robot needs to judge its own direction. Generally, the zero-degree direction is taken as the attack direction. If the robot is not pointing to the zero-degree direction, the adjustment program needs to be run to adjust the robot to the zero-degree direction. Secondly, the robot needs to determine its position in the field. Only by determining its position in the field can the robot choose a suitable offensive strategy. Third, the robot finds the ball through compound eyes. If you have the ball, you will chase the ball; if you don't have the ball, you will go to the center, that is, go back to your goal. Fourth, if the ball is in front of the robot, it is necessary to determine which channel of the front compound eye found the ball, and then choose a different offensive strategy. Finally, if the ball is behind the robot, the robot needs to defend own goal. Prevention of own goal will be discussed in detail in comprehensive practice.

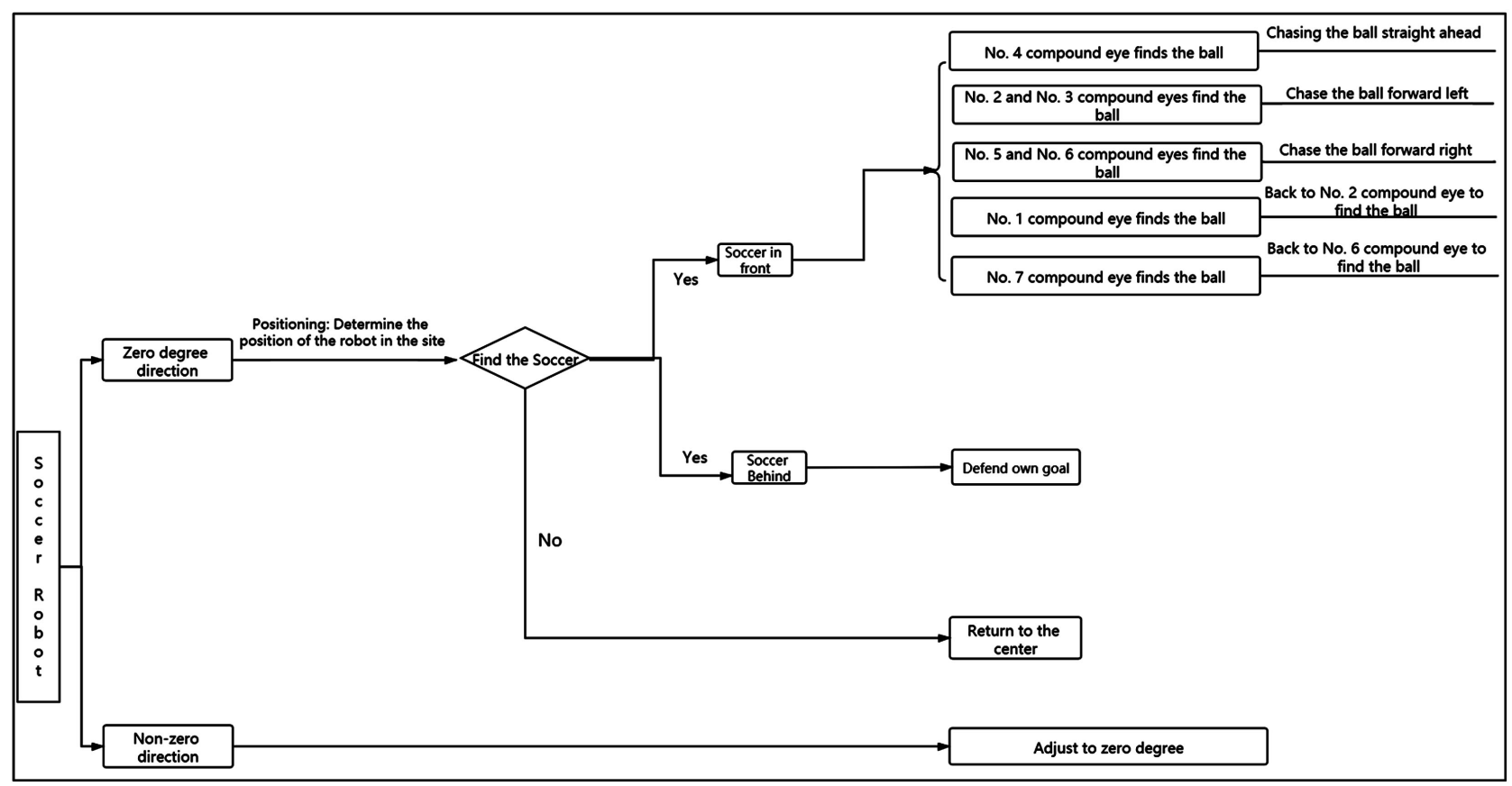

Figure 2. Football robot attack. 
2) Comprehensive Practice 2: defend own goal

Task description: When the ball is behind the robot, prevent the ball from entering the goal.

Task analysis: The processing strategy of the ball behind the robot is shown in Figure 3. First, determine if the robot is pointing in the attacking direction. Generally, set zero-degrees as the direction of the opponent's goal, that is, 0 to 90 degrees, and 270 to 360 degrees as the offensive direction. If the robot is pointing in the offensive direction, it needs to be dealt with an own goal. If the robot is pointing in the defensive direction, then the offense is executed. Then, defend own goal. That is, according to the different channels through which the rear compound eye finds the ball, choose different strategies to prevent an own goal.

\subsubsection{Training "Do-While Loop" Based on Soccer Robot}

1) Experimental significance

Do-while loop occupies an important position in program design. This experiment allows students to learn the do while loop by controlling the movement of the robot, understand the basic idea of the loop structure, cultivate their logical thinking ability, and lay a good foundation for robot program design.

2) Design ideas

Do-while loop is a difficult point in program design, and it is also very important. If you cannot effectively understand the execution process of the do while loop, it is difficult to truly understand the usage of the do while loop. Through the motion state of the robot, students are guided to understand the execution process of the do-while loop, track the change process of the loop variable, and experience the fun of writing programs to control the robot.

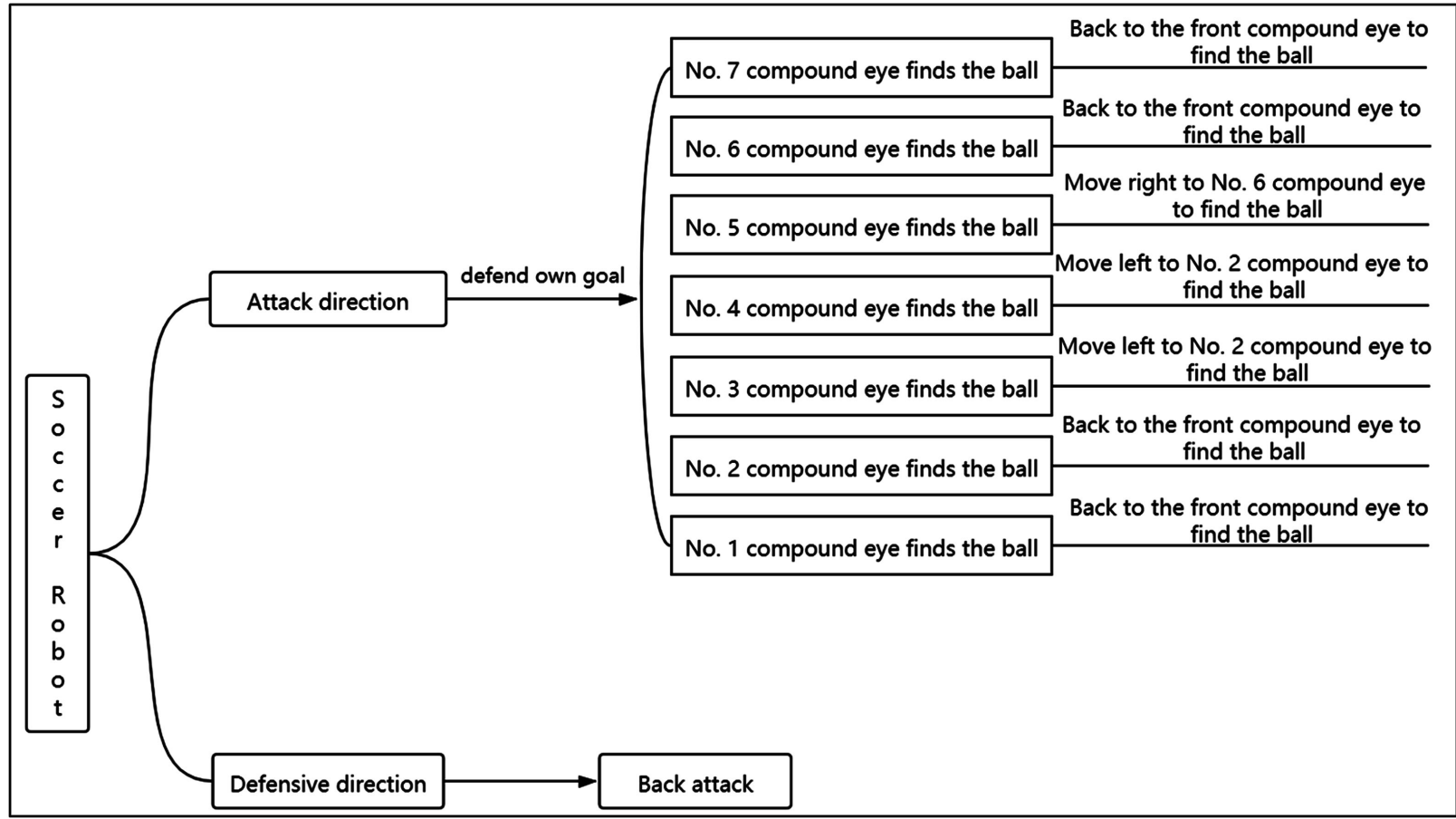

Figure 3. Defend own goal. 
Determining whether the current variable satisfies the loop condition is an important criterion for do-while loop. This function plays a very important role in controlling the movement of the robot and requiring the robot to make various actions.

\subsection{Teaching Experiment Process}

\subsubsection{Teaching Practice Environments}

The experiment is carried out in the computer network room. The computer network room is equipped with teaching equipment such as multimedia broadcasting teaching systems, projectors, etc. The teachers can give full and effective explanations, planned guidance, and prompts of appropriate benefits, in order to stimulate students' enthusiasm for independent exploration. The computer network room is arranged according to the group study requirements, with one table for every four students. There are two robot soccer fields behind the machine room for students to run robots.

\subsubsection{Assembly of the Robot}

Soccer robot competition requires players to assemble robots and write robot programs according to the requirements, and finish the football match by controlling the robot autonomously through the programming. Robot design is a realistic problem that needs program control to solve. Students need to design programs to solve this problem.

The robot products used in this study are some spare parts, which need to be built into a whole robot by students to carry out follow-up work. The key to robot education is the design of robot software, which is essentially a computer program. Students write and debug the program to let the robot independently detect various conditions of the environment, make judgments through their own detection to complete various tasks.

\subsubsection{Teaching Practice}

1) Review introduction

The teacher puts forward a problem, allow the students to use the knowledge they have learned to solve the problem, which will cause conflicts of thinking, guide students to explore more perfect solutions, and lead to new learning content. For example, the teacher asks students to use a do while loop to calculate the sum of all integers between 1 and 100 .

2) Strengthen knowledge points

Through the teacher's explanation, students can firmly grasp the general form and execution process of the do while loop, and understand the concepts of loop variables, loop conditions, increment and decrement.

3) Simple to use

Ask students to think about how to use do-while loop to control the repetitive actions of the football robot. How to start? When will it end? By applying the prior knowledge to control the soccer robot, the simple problem of repeated actions of the soccer robot is solved, and the loop structure of do while is further 
understood.

For example, students are required to design a robot program and use the do-while loop to control the movement of the robot. In each cycle, the robot moves forward and backward, that is, the robot moves forward a certain distance, then moves backward a certain distance, and then stops moving for 10 seconds. Then, every time the loop variable is displayed on the LCD screen of the robot, it must go forward, backward, stop and move back and forth 10 times.

4) Knowledge transfer

Design variant exercises to allow students to try variant applications of knowledge, deepen their understanding of knowledge and skills, consolidate and improve the knowledge content they have learned.

5) Intensive training

Design intensive training to strengthen students' skills in applying the knowledge they have learned to firmly grasp the content of the knowledge they have learned. At the same time, two problems were designed to develop students' thinking ability and cultivate their thinking methods by analogy.

\section{Result}

After a semester of teaching practice, all students participating in the course were post-tested. 707 questionnaires were sent out and 701 questionnaires were returned, with a recovery rate of $99.15 \%$.

\subsection{Data Analysis and Conclusion}

\subsubsection{Analysis of Academic Performance}

1) Academic performance

Comparing the student academic level test scores of the control class and the experimental class, it is found that average score in the control class is 70.74 , the highest score is 94 , the lowest score is 37 , and the experimental class average score is 80.75 , the highest score is 100 , and the lowest score is 21 . In terms of average grades, the academic performance of the students in the experimental class is better than the academic performance of the students in conventional teaching.

2) Results of significance test of difference

Use SPSS 24.0 to perform "independent samples T test" on the two sets of results, and the results are shown in Table 2.

From the output results, we can see that the F value of score is 10.078 , and the associated probability is 0.002 , which is less than the significance level of 0.05 . Therefore, the hypothesis of homogeneity of variance is rejected, that is, the academic level test scores of the control class and the experimental class are not uniform. The concomitant probability of the T-statistic is 0.000 , far less than the significance level of 0.05 , rejecting the null hypothesis of the T-test, that is, there is a significant difference between the academic achievement test scores of the control class and the experimental class. 
Table 2. Independence samples T-Test.

\begin{tabular}{|c|c|c|c|c|c|c|c|c|c|c|}
\hline \multicolumn{11}{|c|}{ IndependenceSamplesT-Test } \\
\hline & & \multirow{2}{*}{\multicolumn{2}{|c|}{$\begin{array}{l}\text { Levene's Test } \\
\text { for Equality } \\
\text { of Variances }\end{array}$}} & \multicolumn{7}{|c|}{ Test for Equality of Means } \\
\hline & & & & \multirow{2}{*}{$\mathrm{t}$} & \multirow{2}{*}{ df } & \multirow{2}{*}{$\begin{array}{c}\text { Sig. } \\
\text { (2-tailed) }\end{array}$} & \multirow{2}{*}{$\begin{array}{c}\text { Mean } \\
\text { Difference }\end{array}$} & \multirow{2}{*}{$\begin{array}{l}\text { Std Error } \\
\text { Difference }\end{array}$} & \multicolumn{2}{|c|}{$\begin{array}{l}\text { 95\% Confidence Interval } \\
\text { of the Difference }\end{array}$} \\
\hline & & $\mathrm{F}$ & Sig. & & & & & & Lower & Upper \\
\hline \multirow{2}{*}{ Score } & Equal variances assumed & 10.078 & 0.002 & -17.434 & 1420 & 0.000 & -10.01117 & 0.57423 & -11.13760 & -8.88474 \\
\hline & Equal variance not assumed & & & -17.421 & 1392.075 & 0.000 & -10.01117 & 0.57465 & -11.13845 & -8.88389 \\
\hline
\end{tabular}

In addition, from the $95 \%$ confidence interval of the difference, the upper limit of the confidence interval is -11.13845 , and the lower limit is -8.88389 . The interval does not span 0 , which indicates that the academic performance of the control class and the experimental class are significantly different.

To conclude, $\mathrm{T}$ test results shows that there are significant differences between the academic proficiency test scores of the control class and the experimental class. According to the comprehensive mean, we can determine that the academic performance of the experimental class is significantly better than that of the control class.

\subsubsection{Data Analysis of Academic Survey}

1) Statistics and distribution of academic survey data

Analyzing the academic survey data of control class and experimental class, the distribution is shown in Table 3.

As shown in Table 3, students of the control class and the experimental class have little difference in their preference for programming courses, firmness of elective programming courses, and expectations of promoting the development of individual abilities in all dimensions of programming courses. However, after a semester of study, the control class under the traditional teaching mode has dropped significantly in all dimensions, while the programming course supported by robotics education has risen slightly in all dimensions, and has greatly improved in the development of cooperation ability and the necessity of starting classes.

To further explain the reasons leading to the above results, the author randomly selected 5 students to conduct interviews on the above phenomenon. The students in the control class generally believed that: a) A pure programming course is too difficult, and it is always difficult to adjust the program. b) I learned the $\mathrm{C}$ language for a semester, but I do not know where it can be used. c) I just know that the $\mathrm{C}$ language is very important, but I just can't get into the state, I always feel very far away from me. The experimental class students do not have the above-mentioned entanglement and depression. They generally hold a positive attitude towards program design, thinking that it is fun to control robots with program codes, and whenever they use programs to control the movement of the robot, they will feel excited and have a sense of accomplishment. 
Table 3. Academic survey data and statistical results.

\begin{tabular}{|c|c|c|c|c|c|}
\hline \multirow{2}{*}{\multicolumn{2}{|c|}{ Question }} & \multicolumn{2}{|c|}{ Control class } & \multicolumn{2}{|c|}{ Experimental class } \\
\hline & & Beginning & End & Beginning & End \\
\hline \multicolumn{2}{|c|}{$\begin{array}{l}\text { The proportion of people who like } \\
\text { programming courses }\end{array}$} & $77.35 \%$ & $51.42 \%$ & $78.68 \%$ & $87.87 \%$ \\
\hline \multicolumn{2}{|c|}{ The firmness of elective programming courses } & $71.35 \%$ & $46.38 \%$ & $71.67 \%$ & $77.32 \%$ \\
\hline & Hands-on ability & $22.13 \%$ & $2.00 \%$ & $20.54 \%$ & $22.58 \%$ \\
\hline $\begin{array}{l}\text { Self-approved } \\
\text { Capacity }\end{array}$ & Logical thinking ability & $31.79 \%$ & $25.41 \%$ & $22.00 \%$ & $23.92 \%$ \\
\hline \multirow[t]{2}{*}{ development } & Innovation capacity & $19.56 \%$ & $3.47 \%$ & $19.70 \%$ & $18.75 \%$ \\
\hline & Collaboration & $6.75 \%$ & $7.83 \%$ & $7.86 \%$ & $16.19 \%$ \\
\hline \multicolumn{2}{|c|}{ Learn a lot from the programming course } & $30.70 \%$ & $45.81 \%$ & $31.83 \%$ & $67.79 \%$ \\
\hline \multicolumn{2}{|c|}{ The necessity of setting up programming courses } & $72.31 \%$ & $35.71 \%$ & $73.56 \%$ & $87.59 \%$ \\
\hline \multicolumn{2}{|c|}{ The necessity of setting up a robot design course } & $83.81 \%$ & $87.86 \%$ & $83.67 \%$ & $87.59 \%$ \\
\hline
\end{tabular}

2) The self-efficacy status and changes of programming courses

The teaching practice of previous programming courses has proved that most students are full of confidence and sufficient sense of self-efficacy at the beginning of the semester. However, after a semester of traditional learning mode, nearly half of the students will have a decreased sense of self-efficacy and have a strong sense of frustration. Therefore, this study paid special attention to the changes of self-efficacy of students in the experimental class before and after the academic year.

Based on the data from the academic situation survey, the change data of self-efficacy in programming was obtained. Since the 10 questions faced the same dimension and had very similar values, the mean value of all the answer values of each student was taken to obtain the statistical data as shown in Table 4.

The independent sample T-test was carried out on the post-test data, and it was found that the test probability $P$ of the 10 questions of self-efficacy was all less than 0.05 , and the mean value of the experimental class was significantly higher than that of the control class.

The "Independence Samples T-Test" was used to test the difference in the post-test data of the experimental class and the control class. It was found that the test probability $\mathrm{P}$ was less than 0.05 on the 10 questions of self-efficacy, and the mean value of the experimental class was significantly higher than that of the control class.

Under the traditional mode of teaching-learning, students' self-efficacy in the programming course decreases quickly after a semester's learning, and they feel more frustrated. The programming course based on robotics education provides students with a good learning carrier, improves their confidence in programming, and makes their self-efficacy develop well.

3) Self-evaluation of experimental class students on academic achievement 
Table 4. Students' self-efficacy class mean and standard deviation.

\begin{tabular}{ccccccccc}
\hline \multirow{2}{*}{ Index item } & \multicolumn{3}{c}{ Control class } & \multicolumn{3}{c}{ Experimental class } \\
\cline { 2 - 8 } & \multicolumn{2}{c}{ Beginning } & End & \multicolumn{2}{c}{ Beginning } & End \\
\hline Self-efficacy performance of students & 3.76 & 1.38 & 2.37 & 1.56 & 3.79 & 1.38 & 3.82 & +1.21 \\
\hline
\end{tabular}

Analyzing the post-test data of the survey we can see that students hold a favorable attitude towards supporting the information technology course teaching of robot education in senior high schools. They put forward valuable opinions on the information technology curriculum teaching of robot education support in senior high school from the aspects of learning resources, teaching methods and curriculum design.

In terms of learning resources, students expect teachers to provide regular curriculum materials and targeted internet resources, especially examples of robot making, such as example programs.

By comparing the pre-test and post-test data of organizational teaching, as shown in Table 5, we found that $63.26 \%$ of the students preferred the teaching method that "teachers give priority to the learning of basic knowledge and carry out self-inquiry learning of applied knowledge under the guidance of teachers". This was a reduction of $6.66 \%$ from the pre-test data. $27.08 \%$ of the students chose the teaching mode of "student-centered self-inquiry learning", which was $6.75 \%$ higher than the previous data. Students have a strong sense of autonomy and sense of achievement through designing and debugging the program to control the movement of the soccer robot. Students hope to understand the basic knowledge of program design and robot through the teacher's teaching, and they also hope to explore how to control the robot through the program under the guidance of the teacher.

In terms of curriculum design, students expect teachers to provide systematic learning materials and adequate learning equipment, and they also expect teachers to provide effective supervision and guide their self-inquiry learning.

After analyzing the survey data of the above questions, we find that students think it is necessary to set up information technology courses supporting robot education in senior high school. They not only hope to get more systematic basic knowledge from teachers, but also hope to conduct self-exploration under the guidance of teachers. It shows that teachers should pay more attention to guiding students' independent inquiry learning in future teaching.

\subsubsection{Analysis of Learning Attitude and Motivation of Programming Courses in Different Modes}

Classroom attendance and students' active participation in the course can reflect students' attitude and learning motivation.

1) Attendance data

The data of attendance of students from the experimental class and the control class participating in the course of algorithm and programming were shown in Table 6. 
Table 5. The test data of the experimental class students on organizational teaching.

\begin{tabular}{ccc}
\hline \multirow{2}{*}{ organizational teaching } & \multicolumn{2}{c}{ Experimental class } \\
\cline { 2 - 3 } & Pre-test & Post-test \\
\hline students' self-inquiry learning is the main & $20.33 \%$ & $27.08 \%$ \\
teacher's lecture in the main & $6.64 \%$ & $9.66 \%$ \\
teachers teach basic knowledge and guide students \\
to explore applied knowledge independently
\end{tabular}

Table 6. Attendance comparison.

\begin{tabular}{ccccc}
\hline & late for class & leave early for class & ask for leave & absenteeism \\
\hline Control class & 472 & 89 & 193 & 120 \\
Experimental class & 96 & 70 & 45 & 22
\end{tabular}

From the attendance statistics in Table 6, the lateness of control class in the algorithm and programming course is very serious, and there are also more leave and absenteeism. However, the number of students in the experimental class who are late, ask for leave and absenteeism in this course has been significantly reduced.

Through further analysis, we concluded that students' inability to learn, inability to understand and unattractive courses were the main reasons for the serious absence of students in the control class, which was also confirmed by subsequent interviews. The curriculum content of the program design in the experimental class has been integrated with the robot control process, and the students' strong interest and enthusiasm for participation are the reasons leading to the sharp decrease of the phenomenon of attendance violation.

2) Learning attitudes

In the learning process, motivation and attitude are a pair of elements that complement each other and are inseparable. For a long time, traditional programming courses have been unattractive because of their dull and obscure content. Some students even have a strong sense of fear of the course content. The overall level of students' motivation is low, which leads to the ineffective development of information technology teaching. Robot design is used to support the teaching of programming courses, the introduction of the vivid concept of robots in teaching, and the creation of a robot teaching platform experimental environment, which greatly stimulates students' interest in learning and learning autonomy. At the same time, robot selection and robot competition activities have played a good assessment and incentive role, promoted the students' competitive learning, and stimulated their strong mentality for winning.

The improvement of learning attitude directly comes from the improvement of learning interest, and learning interest is the most active psychological component of learning motivation (Chen \& Liu, 2007). Therefore, the improvement of learning attitude also reflects the improvement of learning motivation. 


\subsection{Discussion}

\subsubsection{The Integration of Robot Design into Programming Courses Can Improve the Teaching Quality of Courses}

The integration of robot design into programming courses can improve the teaching quality of the courses. Comparing and analyzing the academic level test, we find that the academic performance of students who have participated in the IT course supported by robotics education in high school, has been greatly improved. The number of students in the high-score stage has increased sharply, and the overall distribution of student performance is also concentrated in the high-score stage. By exploring the action mechanism of soccer robot and designing the activities of soccer robot, the learning experience of students can be improved, the learning can be promoted, and the teaching quality can be improved. The reasonable design of educational robots and program design have fully aroused students' enthusiasm for learning and mobilized their enthusiasm for learning, and enhanced the promotion of robotics education on learning effects. The use of educational robots and programming to solve problems in a multi-disciplinary way ensures that students' learning motivation is at a high level. Educational robots have a moderate impact on student learning (Zhou, An, \& Han, 2019). Reasonably designing the practical application of the integration of educational robots and programming courses, enriching the supporting resources of educational robots, and actively exploring the mechanism of robots are the keys to improving the promotion of teaching quality by integrating robots into programming courses.

\subsubsection{The Integration of Robot Design into the Programming Course} Improves Students' Sense of Efficacy in the Programming Course

The integration of robotics education into the programming course enhances students' sense of efficacy in the programming course. analyzing the data of the academic survey, the teaching of information technology courses supported by robotics education in high school provides a good learning carrier to students, frees students from boring and obscure pure code writing, and enables students to use what they have learnt. The combination of boring code and interesting robot actions organically increases students' interest and motivation, and transforms students' motivation from traditional "gradually decreasing" to "gradually increasing".

The integration of robot design into programming courses has enhanced students' attractiveness to information technology courses, stimulated students' learning motivation, corrected their learning attitudes, improved their active participation in the classroom, and made them more willing to participate in information technology courses learning. Integrating robotics education into the programming curriculum, students are no longer just learning from technology, but constantly learning from reflection with the help of technical advantages. When students construct their own understanding of knowledge by building robots and designing robot activities, they will have enthusiasm and interest in the knowledge they have learned, and have strong motivation to learn. 
Under the promotion of "learning for use", students' interest is increasingly high, so that students' confidence in the program design has been improved, the level of self-efficacy has also been improved.

\subsubsection{The Integration of Robot Design into Programming Curriculum Promotes the Overall Development of Students}

1) Development of hands-on ability

This study has developed a complete teaching program, in which a lot of experimental activities have been designed, such as building robots and writing offensive robot programs. In addition, in the process of students carrying out experimental activities, teachers should pay attention to guide the active participation of students and create a relaxed atmosphere. In the evaluation link, teachers should pay more attention to the process of experimental activities rather than the results of experimental activities, so that students have a free and relaxed attitude and can enjoy the happiness of experimental activities. In this way, it is more beneficial to students' independent exploration and the cultivation of students' practical ability. Judging from the teaching effect of the course, good results have been achieved indeed. Many students who don't like to use their hands, especially girls, gradually like playing with robots.

2) Development of logical thinking ability

Logical thinking ability refers to a person's ability to think correctly and reasonably. Psychology believes that logical thinking ability can be trained and cultivated. This course is based on the principles of psychology to cultivate students' logical thinking ability. For example, in the teaching experiment of "The Realization of offensive robot", in order to realize the sub-task of robot adjusting direction, teachers guide students to carry out inquiry learning, explore the method to realize the task, and initially develop students' thinking ability. Through self-inquiry learning, students find problems, so the teacher elicits the concept of "inertia", to guide the students' thinking development again. Then, the teacher further guides the students to observe the movement characteristics of the robot (anticlockwise rotation), urges the students to further improve the robot program, and promotes the improvement of their thinking ability. Finally, the teacher guides the students to examine the robot program again from the perspective of competition, elicits the contradiction between "speed and accuracy", promotes the students' deep thinking, and enables the students' logical thinking ability to be fully released and developed at a higher level.

This study designed a lot of practical activities to promote the development of logical thinking ability, which can be planned and gradually develop students' thinking ability. From the effect of the implementation of the course, students' logical thinking ability has been greatly developed, evidenced by the questionnaire and assessment results.

3) Development of scientific research capabilities

Robotics education is a multidisciplinary and comprehensive field, and robot components are also relatively sophisticated equipment. Therefore, we should 
use the robot platform in a rigorous attitude and scientific method to carry out experimental activities. Starting from the tasks of experimental activities, we should have a purposeful, planned and systematic understanding of the nature and rules of these tasks, and finally complete the tasks.

\section{Summary}

This study constructed and carried out the teaching scheme of programming course supported by robotics education in high school. The teaching of programming course supported by robotics education in high school improves the students' practical ability, scientific research ability and logical thinking ability, increases the students' sense of self-efficacy, and enables students' to understand the basic logical structure better such as do-while loop and branch. Through abundant activities of experimental teaching, students can carry out exploratory practice more confidently and freely, and can guide practical activities with a more scientific attitude and strict thinking. In summary, the teaching of IT courses supported by robotics education is conducive to the development of students' thinking ability and the improvement of their various skills.

\section{Acknowledgements}

We are grateful to Beijing Normal University for embracing this research.

\section{Conflicts of Interest}

The authors declare no conflicts of interest regarding the publication of this paper.

\section{References}

Alshaigv, B. (2013). Development of an Interactive Learning Tool to Teach Python Programming Language. Innovation and Technology in Computer Science Education, July 2013, 344. https://doi.org/10.1145/2462476.2465601

Chen, Q., \& Liu, R. D. (2007). Contemporary Educational Psychology (p. 235). Beijing: Beijing Normal University Press.

Denis, B., \& Hubert, S. (2001). Collaborative Learning in an Educational Robotics Environment. Computer in Human Behavior, 17, 465-480.

https://doi.org/10.1016/S0747-5632(01)00018-8

Gorrieri, A., \& Ferrari, G. (2015). Irresponsible AODV Routing. Vehicular Communications, 3, 47-57. https://doi.org/10.1016/j.vehcom.2015.01.002

He, Y. (2018). Research on Teaching Design and Application of Junior Middle School Program Design Course Based on Network Learning Community. Wuhan: Central China Normal University.

He, Z., Hu, Y. N., \& Allen (2006). Review on the Educational Value of Robot Competition for Primary and Middle School Students. China Educational Technology \& Equipment, $1,13-15$.

Karahoca, D., Karahoca, A., \& Uzunboylub, H. (2011). Robotics Teaching in Primary School Education by Project Based Learning for Supporting Science and Technology Courses. Procedia Computer Science, 3, 1425-1431. 
https://doi.org/10.1016/j.procs.2011.01.025

Lan, W. F., \& Zheng, B. J. (2012). Conception of Curriculum Construction of Advanced Language Programming. Computer Education, 6, 30-32+67.

Li, X., Zhang, Y., Huang, J., Zhang, M., Zhang, Y., \& Wang, J. (2019). Research on the Influence of STEM + C Teaching Based on Design on Primary School Students' Computational Thinking. China Educational Technology, 11, 104-112.

Liu, J. (2009). Relying on Robot School-Based Textbooks to Implement Robotics Education. Experiment Teaching and Apparatus, 12, 52-53.

Liu, M. Y., Xu, Y. H., \& Zhou, S. Y. (2017). Outcomes-Based Teaching Design of "Python Programming". Computer Knowledge and Technology, 13, 105-107.

Nourbakhsh, I. R., Crowley, K., Bhave, A., Hamner, E., Hsiu, T., Perez-Bergquist, A. et al. (2005). The Robotic Autonomy Mobile Robotics Course: Robot Design, Curriculum Design and Educational Assessment. Autonomous Robots, 18, 103-127. https://doi.org/10.1023/B:AURO.0000047303.20624.02

Peng, M. X. (2009). Research on the Design and Development of the Three-Dimensional Teaching Material for Primary School Robotics Education. Xian: Shaanxi Normal University.

Ran, Y. H. (2018). Student Academic Achievement Is Teacher Achievement: The Teaching Quality Control Logic of Chinese Basic Education. Journal of Shanghai Educational Research, 12, 5-8+42.

Sergeyev, A., \& Alaraje, N. (2010). Promoting Robotics Education: Curriculum and State-of-the-Art Robotics Laboratory Development. Technology Interface Journal, 10.

Singh, M., Jain, S., \& Saha, S. K. (2008). Robotic Competition Based Education in Engineering (RoC-BEE). National Conference on Mechanism Science and Technology: From Theory to Application, National Institute of Technology, Hamirpur, 13-14 November 2008.

Verner, I. M. (1998). The Value of Project-Based Education in Robotics. In RoboCup-97: Robot Soccer World Cup I (pp. 231-241). Berlin: Springer. https://doi.org/10.1007/3-540-64473-3 63

Wang, Y. Q. (2004). Exploration and Thinking on the Construction of Robot Laboratory in Primary and Middle Schools. Information Technology Education in Primary and Secondary Schools, 12, 24-25.

Zhang, J. P., \& Wang, Y. (2006). Robotics Education: Status, Problems and Advancing Strategies. China Educational Technology, 12, 65-68.

Zhang, W., \& Zhao, Z. W. (2012). Research on Teaching Method of VB Language Program Design for Computer Major. Scientific and Technological Innovation, 32, 214.

Zhang, X. H., Duan, J. L., Zhou, Y., \& Li, W. D. (2019). Discussion on the Course Reform of "VB Program Design". Education Teaching Forum, 31, 66-67.

Zhou, J., An, T., \& Han X. J. (2019). Meta-Analysis of the Impact of Educational Robots on Students' Learning. Modern Distance Education Research, 3, 96-105. 